\title{
Continuing professional training as a factor of teachers' professional and career growth
}

\author{
I. Ye. Kopchenko ${ }^{1 *}$, I.A. Tvelova ${ }^{2}$, and V.M. Khlopkova ${ }^{3}$ \\ ${ }^{1}$ Armavir State Pedagogical University, Armavir, Russia \\ ${ }^{2}$ Armavir State Pedagogical University, Armavir, Russia \\ ${ }^{3}$ Armavir State Pedagogical University, Armavir, Russia
}

\begin{abstract}
The article provides the analysis of modern trends in the development of education that call for steady professional advancement and improvement of professional competencies of teachers. The main vectors of teacher's professional and career growth are defined. The role of continuing professional training as a leading factor of improving pedagogical activity in the modern changing world is emphasized. The main directions and goals of the development of continuing training within the field of study "Pedagogical Education" and the experience of implementation in Armavir State Pedagogical University are considered.
\end{abstract}

\section{A problem statement}

Based on global forecasts the coming decade will be accompanied by challenges and transformations in education and the real sector of economy. Social systems function under constant change. The world labor market is undergoing significant modifications that lead to the emergence of new professions or the disappearance of existing ones. The very notion of "profession" is becoming obsolete; it is being replaced by a flexible set of skills and competencies necessary to solve particular problems. Stable career paths that existed before are not relevant any more.

The world is becoming more unpredictable and volatile; highly specialized knowledge is increasingly required to be updated. Moreover, such knowledge does not necessarily lead to success in a world where you need to quickly learn and retrain, adapt flexibly, improvise and work a lot in teams (high-tech products require coordinated work of different specialists). This means that the old ways of assessing knowledge and skills are no longer working. New assessment systems imply independent thinking, resistance to uncertainty and flexible skills.

In the nearest future, such changes will affect the sphere of education and retraining that should be prepared to develop relevant programs in the short terms and to form contents with maximal flexibility.

Education is traditionally considered a conservative sphere but due to new information and communication technologies, it is beginning to change significantly. First of all,

* Corresponding author: ipcs-profped@yandex.ru 
education ceases to be just a stage at the beginning of an independent life but becomes an ongoing process that accompanies a person throughout his/her life.

In the era of lifelong education, not only the duration of education but also its mechanisms are changing; new professions appear in this area. Knowledge becomes obsolete very quickly, so educators and everyone who works in the field of education should reconsider priorities and learn to make up complex educational tracks, to supervise creative projects and to use the latest advances in information technology and neuroscience. The flexibility of educational institutions of secondary and higher professional education plays an important role in training personnel for the new economy.

Any university, no matter how prestigious it is, does not keep pace with the dynamics of the labor market. Fundamental education is attractive because a person cannot only master some specific skills but learns to study and think structurally. That is, these skills will have to be acquired while engaging in professional activity.

Therefore, investments in education, reconsidering basic educational programs and programs of continuing professional training are paramount nowadays. These tasks have already become part of the state strategy for the development of education. But at the same time, teachers themselves must take responsibility for lifelong learning.

\subsection{The objective of the work}

The traditional educational system that consists of closed elements in the form of typical educational organizations with standard educational programs is transforming into a flexible ecosystem, in which educational elements of different formats and scales coexist, from large campuses, open online platforms to small centers and mobile applications.

Consequently, the approaches to the study of theoretical and applied problems of the development of education are changing. Within the systematic approach, which makes it possible to consider various aspects of the development of education comprehensively, an idea of education as an ecosystem is being currently formed.

In general, the ecosystem approach is gaining popularity in social research; its essence consists in the study of ecosystems as complex networks and their interactions. Education is also a complex ecological system [1].

Continuing professional education is also part of this system. The ecosystem approach is reflected in the guidelines on the creation of centers for steady professional development of teachers within the federal project "A Teacher of the Future" of the national project "Education" [2].

\section{Materials and the results of the research}

This document manifests the idea that "a teacher who possesses key professional competencies, who can use the newest educational technologies and is engaged in an active process of maintaining and developing this ecosystem is its most important element. The educational ecosystem must be continuously renewed thereby providing learners with new educational opportunities. The educational process in this case is supported by new educational technologies and constantly modernized content oriented towards practice and the changing socio-cultural situation" [3].

A.I. Zhilina noted, "In the XXI century, society set a truly historic task for teachers: to ensure high professionalism and functionality of a person under global changes within a single generation." Accordingly, they must master "not only new educational technologies and methods of teaching and upbringing of the younger generation but also achieve the long-term goals, which implies a change in the methodology of teacher's 
professional activities." Updating and improving relevant competencies is carried out within continuing education courses [4].

According to V.M. Khlopkova and O.G. Karapkova, "Modern pedagogical education is being updated faster in accordance with scientific achievements and social demand and is more practice-oriented. A graduate of a pedagogical university develops the acquired competencies at the subsequent stages of professional education as well as in the process of professional activity and mastering professional advanced training and retraining programs. Multilevel professional training is based on the principle of integrity of different educational structures" [5].

There is a reason that teacher's profession calls for continuous learning throughout the entire period of professional activity. This is not only a condition for career growth but also a prerequisite for successful work in this professional field. I.A. Korshunov, K.S. Kuzheleva, B.A. Grachev and K.A. Sergeyev note that "programs of continuing professional education are mostly in demand in the field of education, health care and social services, which is ensured by the internal regulations of the industries that require mastering relevant educational programs." At the same time, the share of educational workers who mastered continuing professional education programs is greater than in any other industry, for example, in 2016, it amounted to $18.6 \%$ [6].

The model of professional standard of pedagogical activity based on the systemactivity approach includes a set of competencies that ensure the solution of the main functional tasks of a teacher. The concept of competence is ambiguous. The team of authors of the monograph "Professionalism of a modern teacher. The methodology for assessing the level of qualifications of teaching staff" understands competence as "systemic manifestation of knowledge, skills, abilities and personal qualities that allow successfully solving functional tasks that make up the essence of pedagogical activity." The qualification of a teacher can be characterized by a level of developed competencies "in terms of personal qualities, in setting goals and objectives of professional activity, in motivating students to carry out educational activities, in developing an activity program and making pedagogical decisions, in providing an informational activity basis and in organizing pedagogical activities" [7].

Motivating employees for career growth is one of the relevant problems of building a successful career. The main motivators stimulating effective work and attachment to the workplace, as noted by Yu.A. Lukash, are opportunities for career, personal and professional growth provided by the employer. There are two approaches (administrative and competence-based) to motivate personal career growth. At the same time, hierarchical incentives in within the administrative approach imply the occupation of high-ranking positions and the desire for administrative activity. Within the competency-based approach a person seeks to acquire as much knowledge as possible, to be recognized by colleagues and to transfer knowledge to others. A combination of these two approaches is considered optimal for harmonious alignment, which is fair. Moreover, career growth can be conditionally subdivided into "horizontal" (qualitatively new responsibilities and projects, which allows expanding the professional horizons, acquiring the status of a high-class specialist) and "vertical" (moving to the next step of the career ladder, a higher level of structural hierarchy) [8].

The specifics of teaching, including the need for a continuous process of learning and self-improvement, imply proper motivation for this activity, without which professional and career growth is impossible. The problem of motivation for pedagogical activity and professional personal growth of a teacher is one of the main areas of research of the indicated problems. I.A. Tvelova notes that "solving the problem of purposeful formation of a stable positive attitude towards the teaching profession in the process of training at a pedagogical university, the formation of a stable positive attitude towards the teaching 
profession as a prerequisite for the success of teacher's professional activity is a necessary condition for personal and professional development. The choice of the sphere of professional activity is a component of the structure of professional self-determination, the essence of which is to independently and consciously find the meanings of the chosen future profession. Professional self-determination is an integral part of personal selfdetermination" [9].

Such attention to motivating pedagogical activity is not accidental since teaching is not only a profession but also a vocation. Difficulties in the professional growth of a teacher often make the graduates of pedagogical universities to choose another area. Nowadays, there is a shortage of teaching staff. This fact is presented in analytical reviews. For example, D.P. Platonova, K.V. Zhitkov, P.V. Demin and S.G. Pilipenko note, "For several years, the annual number of graduates in the enlarged group of specialties and areas of training "Education and Pedagogical Science" has been about 100 thousand people. This is much fewer than 10 years ago. The share of graduates within the group "Education and Pedagogical Sciences" in the total amount of graduates also decreased, from $11 \%$ in 2005 to $8 \%$ in 2015 . At the same time, "another important characteristic is a decrease in the proportion of young (20-29 years old) teachers accompanied by an increase in the proportion of teachers aged 50-59 years" [10].

This problem is part of the global process of changing professional orientations in various industries. In 2016, the World Economic Forum (WEF) prepared a labor market report entitled "The Future of Jobs - Employment, Skills and Workforce Strategy for the Fourth Industrial Revolution". Since then, the dynamics in this area have intensified and there have been changes in the labor market. "The analysis of the labor market shows that the efforts of employers are aimed at retraining and advanced training only for highly qualified and valuable employees. However, in order to embark on a winning strategy in relation to human resources, enterprises need to evaluate investment in human capital as an asset but not as costs" [11].

By 2022, an increase in the number of new professions is expected in all sectors, which will contribute to an increase in employment. It is estimated that companies with more than 15 million employees will have lost 0.98 million traditional jobs and created 1.74 million new jobs by 2022. "Professions that use unique human-only skills such as empathy, socialemotional intelligence and creativity will become particularly popular. These professions include customer service workers, sales and marketing professionals, development specialists and innovation leaders." Although the teaching profession is not represented in this list, all of the above skills are associated with educational professional competencies. It can be assumed that these professions can be transformed in terms of educational activities. As a result, 54\% of employees will need to improve their qualifications or retrain [12].

Global changes taking place both in Russia and around the world set a number of fundamentally new tasks for educational organizations such as developing and improving educational systems and introducing innovations. In this case, we are not talking "about innovations from above implemented through reforms but about initiatives from below." When assessing the availability of infrastructure for innovation, the authors of a study conducted by the Institute of Education of the National Research University of the Higher School of Economics (D.O. Koroleva, T.O. Naushirvanov) noted the factors that hinder its development. In addition to "the lack of funding and resources such constraining factors include a staff shortage associated with the lack of necessary competencies among teachers, the reluctance of young people to work in the field of education, the lack of knowledge in the field of business planning and marketing among teachers, weak motivation to innovative activity, psychological barriers" [13].

In addition to external factors, a favorable economic situation, stimulating state financial support, special contests and platforms for promoting and implementing ideas, 
digitalization of education the drivers for the development of educational innovations include the growth of activity and interest of society in the development of education, an increase in the activity of participants in educational systems, high personnel potential [14].

One of the main mechanisms for increasing the level of human resources is continuing education, where teachers acquiring new or improving existing competencies can increase motivation and master the methods of creative thinking. The system of continuing education should undoubtedly be innovative in nature, meet the needs of modern society and be guided by the goals of long-term development.

Among the priorities of the system of continuing professional education for the implementation of state educational policy A.I. Zhilina notes "the comprehensive provision of the availability, quality and frequency of continuing professional education, the development of a system model of continuing professional education as a strategic resource for the development of pedagogical personnel on the basis of flexibly organized forms of study throughout the teacher's working life, strengthening the implementation of compensatory and adaptive functions of continuing pedagogical education." At the same time, it is necessary to overcome a number of difficulties of continuing professional education such as "inconsistency with the requirements of professional standards, the unaddressed nature of a certain part of continuing professional education programs, a gap between content, technology and educational results, functional illiteracy (methodological, legal, technological, political, social-communicative, general cultural, behavioral)" [15].

The national project "Education" pays much attention to the professional growth of a teacher. The federal project "Teacher of the Future" is aimed at creating growth points in the educational environment for professional and career prospects of teachers, at building an effective system of continuous professional development of teachers based on fundamentally new organizational and substantive approaches to the system of advanced training of teachers and to assessment of their competencies.

Technologies and markets are changing rapidly, thus, it is relevant to talk not about choosing a profession but about choosing a field of activity and competencies that are needed for a successful career. It is very difficult to predict the demand and success of professions in the long term. In any case, it is necessary to link the forecast of the professions of the future to the technologies of the future and the development of industries. The process of choosing a profession itself can be lengthy (sometimes continuous) and in no case ends at the level of general secondary, vocational and higher education. Each level only develops an understanding of the profession and the competencies necessary for it.

In modern continuing professional education, two training models can be distinguished: "the adaptation model aimed at adapting a teacher to changing conditions of the current professional activity and the model of professional development focused on teacher active actions, the ability to make decisions and take responsibility for own actions in a new kind of professional activity" [16].

It is obvious that traditional forms of education do not fully satisfy the needs for educational services. Some people who needed educational services did not have the opportunity to receive them in a traditional way within the existing educational system. The traditional training system has long been unacceptable for educational institutions which are faced with a constant shortage of teachers due to their absence for the period of retraining and advanced training.

Expanding the possibilities of using distance educational technologies opens up new opportunities but also creates new challenges. These technologies themselves do not solve the problem of improving the quality of continuing education. The search for new ways to increase mobility and flexibility of the system of continuing education resulted in establishing centers for continuous improvement of teaching professional skills; these 
centers also fulfil intermediary functions between teachers and organizations that implement programs of continuing professional education [17].

New forms of education, including e-learning and distance learning technologies are a way out of this situation. Presently, distance learning, on the one hand, is a very popular form of education; in the developed countries it has existed in its modern form for over 30 years and is an integral part of the world educational system covering all levels of education. On the other hand, this is a necessity under current circumstances.

The very idea of distance learning is not new for Russian education and has long been used by leading Russian universities. Due to the COVID-19 situation, this technology is now used throughout the country as it allows protecting students and teachers, preventing the spread of the infection and, at the same time, ensuring the continuous implementation of educational programs.

Combining the best features of other forms, e-learning and distance learning technologies are promising forms of education. They are a more democratic form of education as well since anyone, regardless of age and social status, can get and improve qualifications, reorient in professional activity, combine study with work, complete an educational program in a short time.

However, the success and effectiveness of any form of education depend on the organization of quality assessment since only well-organized control and the correct use of its results contribute to ensuring the quality of education.

The rapidly changing economic situation, the impact of the COVID-19 pandemic, environmental disasters as well as political conditions are catalysts for the creation of new educational products that meet the current needs of economy and social sphere including the lifelong learning system. In the short term, any profession will require updating knowledge and skills every three months. This is the minimum amount of time a person will have to spend on training to fit the labor market.

Given the fact that an educational system cannot change quickly, it is appropriate to talk about the implementation of the adaptation model, though there are many difficulties. The situation that has developed in connection with the forced accelerated transition to distance learning proves it.

This transition has created many challenges for teachers. According to the results of a study by the Institute of Education of the Higher School of Economics, within which 22,600 teachers from 73 regions of the country were interviewed, before switching to distance learning, $64 \%$ of teachers used educational online platforms regularly or from time to time mainly due to the need to work out complex topics and to do homework. About half of teachers used various online resources during school lessons from time to time and more often... During the transition of schools to distance learning, the proportion of those who use online resources in their work increased from $64 \%$ to $85 \%$. At the same time, $3 / 4$ of teachers who had not previously used any educational online resources began using them. Of these, $47 \%$ noted that they will most likely continue to use them in their work in the future [18].

It should be noted that the change in the usual practice of teaching and working with students has become a stress for all participants of the educational process. The overwhelming majority of teachers $(84 \%)$ believe that with the transition of schools to distance learning their workload has increased; $59 \%$ noted that the load on children has also increased [19].

The increase in workload is connected, "first of all, with the need to quickly master new learning formats, prepare for classes in a different way as well as with the violation of the usual practice of giving lessons and interacting with colleagues, students and parents. Secondly, not all teachers know how to use the opportunities of educational platforms and various digital services. For example, $13 \%$ of teachers did not know that it 
is possible to set homework on an educational platform where the results will be automatically checked; $75 \%$ of the teachers did not give video lessons" [20].

Teaching is an eternal profession. This is a profession in which a person, perhaps, will not be replaced by machines for a long time. But this branch of knowledge is changing; online pedagogy is becoming popular. Advanced training courses and retraining programs are changing current formats. Eventually, in addition to simple video communication (twoway or multi-channel), educators will use interactive tools that will allow receiving feedback from students and immediately check their knowledge. The learning process can become more "alive" than in a traditional classroom.

A teacher, like no one else, must master the profession perfectly and regularly improve qualifications taking into account constantly changing requirements for competencies. This requirement is also enshrined in law: a teacher is obliged to "systematically improve his/her professional level", which determines the need for constant updating and broadening knowledge once acquired and the necessity to form culture of "education throughout life." The system of continuing education, which is changing along with basic education and even ahead of it in a number of parameters, is a tool for the implementation of the given requirements. At the same time, the functionality of continuing education is significantly expanding.

The current system of continuing education is quite diverse. Various organizations are represented on the market of continuing educational services. At the same time, the role of universities as centers of advanced training and retraining of pedagogical personnel is paramount. This is no coincidence. According to research, "For a person who is going to train in a continuing education program the status of an educational organization is of great importance. That is why universities continue to play a significant role regardless of the region, although they do not constitute the largest share among all organizations offering these programs. A study of the websites of universities shows that, as a rule, successful universities offer up to 200 continuing education programs" [21].

The role of a pedagogical university in creating conditions necessary for professional and personal growth of teachers is extremely great. First of all, this task is fulfilled in the course of receiving pedagogical education by students in major programs. Secondly, it is a pedagogical university that can offer continuing professional education programs that meet the needs of teachers. Let us consider the experience of implementing continuing professional education programs and the experience of interaction with educational organizations and teachers aimed at improving pedagogical skills and at exchanging experience at Armavir State Pedagogical University (hereinafter also referred to as ASPU).

In ASPU, continuing professional education is implemented at the Research Institute for the Development of Education and includes a wide range of programs within the field of study 44.03.01 "Pedagogical Education" covering preschool, primary education as well as all school subjects and subject areas at the level of basic and secondary education.

As a pedagogical university ASPU uses various forms and methods of teaching aimed at mastering general professional and special professional competencies necessary for successful work in a modern school.

The participation of university representatives in leading regional and federal events in the field of science and education confirms the social and humanitarian orientation, effectiveness and social significance of the university's work.

ASPU is a modern university in which modern educational trends are maximally taken into account in training future teachers. The university demonstrates an understanding of the modern socio-cultural context of social development, the complexity of the tasks of implementing state policy, the increasingly complex requirements of the labor market and, therefore, builds a successful development strategy. 
The experience in the use of distance educational technologies at the university as well as the experience of widespread introduction of innovative educational technologies into programs of continuing professional education, their use in the theory and methodology of teaching school subjects and in solving relevant issues make it possible to offer general educational organizations (both teachers and schoolchildren) methodological support including with the use of Internet resources.

In this regard, the university holds not only traditional annual events to update major and continuing education but also applies a system of measures to introduce innovative educational technologies aimed at the formation of digital, communicative and entrepreneurial competencies of students.

Paying special attention to the processes of digital transformation in education the university has developed and is implementing advanced training programs such as "Digital Tools in the Work of a Teacher in the Context of Digitalization of Education according to the Requirements of Federal State Educational Standards", "Digital Transformation of an Educational Institution". The development and implementation of these programs became possible on the basis of the competencies formed among the teaching staff of the university following the completion of the educational intensive "Island 10-22" from July 09 to 23, 2019, organized with the support of the Government of the Russian Federation, the Ministry of Education and Science of the Russian Federation, the autonomous non-profit organization "University of the National Technological Initiative 2035" on the basis of the innovation center "Skolkovo Institute of Science and Technology".

The university prepares specialists for modern integrated education; there are several areas for training specialists in special and correctional pedagogy for teaching people with special educational needs in inclusive classes and schools.

ASPU has experience of effective cooperation within the pedagogical community for solving urgent scientific and educational problems.

In 2018, with the use of a grant from the Ministry of Education and Science of the Russian Federation training for rural teachers in financial literacy and methods of educational work with rural population was organized (contract No. FEFLP / QCBS-3.37) under the program of continuing professional education "Fundamentals of Financial Literacy, Methods of its Teaching in the System of Secondary Education and Financial Education of Rural Population".

On October 10-11, 2019, under a grant from the Ministry of Education of the Russian Federation, the Second All-Kuban Congress of Russian Language and Literature Teachers (a scientific conference of the pedagogical community with international participation) was organized and successfully held. It brought together 550 delegates, 50 of them were foreign participants, two are absolute winners of the All-Russian competition "Teacher of the Year of Russia". Positive feedback from the participants of the Second All-Kuban Congress of Teachers of Russian Language and Literature and the existing experience allows the university to introduce into practice a new format of work with teachers of Krasnodar Krai. This new format includes a subject forum, a workshop within which it is possible to consider topical issues of theory and methodology of teaching subjects in the context of Federal State Educational Standards as well as organizing master classes with the participation of the staff of ASPU and experienced teachers of the pedagogical community.

On December 13-14, 2019, at the initiative of the Education Department of the Administration a forum on the Russian language and literature was held in Krasnoarmeisky District. Such events held in individual municipalities will provide an opportunity for subject teachers to participate in the exchange of advanced pedagogical experience and to outline specific ways to improve their professional competencies.

The university has experience in methodological support for schools with the intensive study of particular subjects concerning extracurricular activities, programs of continuing 
general educational and advanced training programs for teachers. The directions of interaction with the departments of education of Krasnodar Krai in organizing work in classes of social-pedagogical orientation are outlined.

The university annually holds the Pedagogical Skills Competition "A Teacher Who Is Awaited!" which is aimed at stimulating pedagogical creativity, increasing the prestige of the teaching profession and creating conditions for unleashing students' professional and creative potential. The formation of personal professional experience and skills in the search and development of innovative pedagogical technologies are also in focus.

Presently, the university implements more than 150 advanced training programs and about 80 professional retraining programs, training in which is carried out including with the use of distance learning technologies. The quality of the implementation of advanced training and professional retraining programs with the use of distance learning technologies largely depends on the level of teachers' proficiency in the relevant competencies. Therefore, teachers should be proficient not only in information and communication technologies but also in the methodology of their use in the educational process.

The effective information support for advanced training and professional retraining programs should contain the following services: a distance learning system for asynchronous work with students, synchronous work services to provide instant feedback between a teacher and students, knowledge testing services, services for accessing multimedia content via the Internet, access services to educational and methodological materials.

The university is working to improve the information support of advanced training and professional retraining programs that is aimed at improving the quality of knowledge and competencies of students; this is achieved through the active implementation of modern interactive multimedia educational services that allow using distance learning technologies in synchronous mode (Zoom, Google Meet). Lectures are uploaded on Youtube and then attached to the learning platform. Testing students can be carried out by means of distance learning systems (DLS), for example, Moodle, or other services such as Google Forms, Quizizz, etc.

Educational video lectures increase the level of mastering educational material by providing its visualization. For additional effectiveness of this tool it is necessary for students to study the summary of a lecture and answer key questions after the lecture is over. Communication in a synchronous mode allows organizing the process of instant feedback when conducting a training session, which is very important for increasing the effectiveness of the educational process.

\section{Conclusions}

Therefore, in the modern changing world, the criteria and mechanisms of professionalism and personal growth of teachers are changing preserving traditional humanistic values as their core. An important task of continuing professional education includes the introduction of modern technologies into the educational process. At the same time, the influence of the human factor, exchange of experience and interaction remain no less significant, no matter a form of communication.

The activities of ASPU in promoting continuing professional education for teachers respond to the needs of modern society. The university as a whole and the Research Institute for the Development of Education in particular respond promptly to constant changes in the educational system, provide teachers with new professional competencies, ensure the continuity and integrity of professional development and implement exclusive programs of continuing professional education aimed at eliminating professional 
pedagogical deficiencies and establishing "points of growth". The possibilities of the best educational practices to organize professional development of teaching staff are also used.

\section{References}

1. Yu.V. Yarovykh, Bulletin of Tomsk State Pedagogical University, 5, 13-17 (2014)

2. National project education: passport of the national project "Education", Russia, access mode: https: //edu.gov.ru/national-project /

3. On the approval of methodological recommendations for the creation and maintenance of centers for assessing professional skills and qualifications of teachers, centers for continuous improvement of professional skills of teachers under the federal project "Teacher of the Future", Russia, access mode: http://docs.cntd.ru/document/561251520/

4. A.I. Zhilina, The Bulletin of Leningrad State University Named after Alexander Pushkin, Part 3, 2, 57 (2014)

5. V.M Khlopkova, O.G. Karapkova, Scientific and educational-methodical yearbook, XVII, 258-259 (2020)

6. I.A. Korshunov, K.S Kuzheleva, B.A. Grachev, K.A. Sergeyev, Live and learn: continuous education in Russia, Live and learn: continuous education in Russia, p. 26 (Moscow: NRU HSE, 2018)

7. A.V. Karpov, I.V. Kuznetsova, M.D. Kuznetsova, V.D. Shadrikov, Methodology for assessing the level of qualifications of teachers: monograph, p. 13-14, access mode: http://www.iprbookshop.ru/9146.html (Moskov, 2011)

8. Yu.V. Yarovykh, Bulletin of Tomsk State Pedagogical University, 5, 13-14 (Tomsk, 2014)

9. I.A. Tvelova, Problems of Modern Pedagogical Education. A collection of scientific papers, 67, part 2, 322-325 (Yalta: EPC HPA, 2020)

10. D.P. Platonova, K.V. Zhitkov, P.V. Demin, S.G. Pilipenko, Education and pedagogical sciences: general trends in higher pedagogical education, p. 14-15 (Moskov: NRU HSE, 2017)

11. The future of workplaces (brief overview), World Economic Forum, Analytical report, p. 2, access mode: https://kpfu.ru/portal/docs/F_2097205868/Budushhee.rabochikh.mest.2018.pdf (2018)

12. The future of workplaces (brief overview), World Economic Forum, Analytical report, p. 7-10, access mode: https://kpfu.ru/portal/docs/F_2097205868/Budushhee.rabochikh.mest.2018.pdf (2018)

13. D.O. Koroleva, O.G. Naushirvanov, The ecosystem of innovative development of Russian education: infrastructural characteristics, $\mathrm{p} 15$ (Moskov: NRU HSE, 2020)

14. D.O. Koroleva, O.G. Naushirvanov, The ecosystem of innovative development of Russian education: infrastructural characteristics, p 18 (Moskov: NRU HSE, 2020)

15. A.I. Zhilina, The Bulletin of Leningrad State University Named after Alexander Pushkin, Part 3, 2, 57-59 (2014)

16. M.E. Weiner, Bulletin of RIAT, 3, 113 (Himki, 2014)

17. On the approval of methodological recommendations for the creation and maintenance of centers for assessing professional skills and qualifications of teachers, centers for continuous improvement of professional skills of teachers under the 
federal project "Teacher of the Future", access mode: http://docs.cntd.ru/document/561251520 (2019)

18. D.I. Saprykina, A.A. Volokhovich, The problems of transition to distance learning in the Russian Federation through the eyes of teachers, p. 7-8 (Moskov: NRU HSE, 2020)

19. D.I. Saprykina, A.A. Volokhovich, The problems of transition to distance learning in the Russian Federation through the eyes of teachers, p. 9 (Moskov: NRU HSE, 2020)

20. D.I. Saprykina, A.A. Volokhovich, The problems of transition to distance learning in the Russian Federation through the eyes of teachers, p. 13 (Moskov: NRU HSE, 2020)

21. A.A. Korshunov, V.M. Gaponova, V.M. Peshkova, Live and learn: continuous education in Russia, p. 22-23 (Moskov: Publishing House of Higher School of Economics, 2019) 